\title{
In vitro Cultivation of Vesicular- Arbuscular Mycorrhizal Fungi and its Biological Efficacy
}

\author{
A.D. Bholay ${ }^{*}$, Sophia Barbosa and Kirti Jadhav \\ Department of Microbiology, K.T.H.M. College, Nashik, SP Pune University, MS, India \\ *Corresponding author
}

\section{A B S T R A C T}

\section{Keywords}

Mycorrhiza, VAM,

Mycorrhizal

dependency,

Hydroponics

\section{Article Info}

Accepted:

10 February 2018

Available Online:

10 March 2018

Crop improvement is significantly enhanced by the application of beneficial microbes. Progress in understanding the biology of mycorrhizal fungi is hampered by the limited number of species that can be successfully propagated and studied in vitro using resting spores. VAM spores were isolated from the rhizosphere soil and were cultivated in-vitro using Cooke Rose Bengal medium. In pot culture experiment, the plants treated with VAM isolates exhibited enhancement in growth than the control ones. After using mycorrhizal inoculum, the root colonization of crop plants was greatly affected. VAM fungal inoculation had significant effect on growth parameters like plant height, weight, MD and root colonization. Since spores could successfully infect wheat, rice and maize roots, this method provides a way of starting a pure-line culture of VAM fungus allowing to study the intraspecific variation of the fungus and to observe the presence, location and different developmental stages of hyphae and new fungal organs at an excellent medium and with a high rate of success and reproducibility.

\section{Introduction}

Biofertilizer is commonly referred to the use of soil microorganisms to increase the availability and uptake of mineral nutrients for plants. Biofertilizer be defined as a substance which contains living microorganism which colonize the rhizosphere or the interior of the plant and promotes growth by increasing the supply or availability of primary nutrient and growth stimulus to the target crop, when applied to seeds, plant surface or soil (Amutha et al., 2014). Mycorrhizaare obligate biotrophs that form mutualistic association between plant roots and fungal mycelia (Jha et al., 2011; Smith et al., 2011). Ninety-five percent of the plant species form mycorrhizae. It can act as a critical linkage between plant roots and soil. This association is characterized by the movement of plant produced carbon to fungus and fungal acquired nutrients to plants. Fungi under VAM are the members of Endogonaceae and they produce an internal network of hyphae between cortical cells that extends out into the soil, where the hyphae absorb mineral salts and water. Mycorrhizal associations produced by Glomeromycotan fungi are known as vesicular-arbuscular mycorrhizas and are abbreviated as VAM. VAM fungus is of value for basic research as well as biotechnological applications because it functions as a plant growth promoter and 
bio-fertilizer in nutrient-deficient soils, imparts bio-protection against biotic and abiotic stresses, as a bio-regulator for plant growth development. VAM fungi provide several other benefits to host plants including tolerance to drought (Aroca et al., 2008) and heavy metals, protection from pathogens, promote seedling establishment and influence plant invasions (Pringle et al., 209). As a result, VAM fungi can have a significant effect in agricultural systems by improving crop growth and productivity. VAM spores were isolated from rhizosphere soil by wet sieving and decanting technique (Gerdemann et al., 1963). Isolated spores were characterized by vital stain and cultivated in vitro on synthetic media.

Cooke Rose Bengal Agar is a selective medium for the isolation of fungi (Cooke, 1954). Selectivity of the medium is increased by the addition of antibiotics. Waksman described an acid medium consisting of peptone, dextrose, inorganic salts and agar for the isolation of fungi from soil. It was discovered that soy peptone was particularly suitable for use in this medium and that the combination of chlortetracycline or oxytetracycline with Rose Bengal increased the selectivity of the medium. Cooke preferred chlortetracycline in Cooke Rose Bengal Agar due to the increased stability of the antibiotic. Peptone provides nitrogen, carbon and vitamins in Cooke Rose Bengal Agar. Dextrose is an energy source. Rose Bengal and chlortetracycline selectively inhibit bacterial growth and restrict the size and height of colonies of more rapidly growing molds. Monopotassium phosphate provides buffering capability. Magnesium sulfate is a source of divalent cations. Agar is the solidifying agent (Cooke, 1954).

The fungi are usually maintained and multiplied in conjunction with suitable host plant roots. Several culture techniques applicable for commercial scale production of bio-inoculum include pot culture, soil-less culture, hydroponic culture, aeroponic culture and axenic root organ culture techniques (Tanzima Yeasmin et al., 2004). In the present study, various plant varieties (maize, rice and wheat) with and without mycorrhiza were cultivated in soil by Pot culture method. To get maximum agricultural benefits, in inoculation of the soil with suitable type of VAM fungi is necessary. Hence, the only way to culture and maintain Arbuscularmycorrhizal fungus production, the use of VAM inoculum that is produced by additional application of this fungus should become commercially feasible. For this reason, pot experiment inoculum production was conducted in the present study for evaluation of the effect of the indigenous mycorrhiza on the growth and nutrients of maize, rice, and wheat plants. The plants that naturally facilitate the higher colonization of VAM can be generally considered to be used as a stock plant. Stock plants to culture the VAM fungi for inoculum preparation for utilization as a biofertilizer were selected in ordered to increase agricultural crops (Tanzima Yeasmin et al., 2004) as well as to minimize the use of chemical fertilizers and thereby reduce the environmental pollution. The objective of this study is to determine the response of these plants to in vitro cultivated VAM.

\section{Materials and Methods}

\section{Isolation of VAM}

In this present work, VAM fungal spores were isolated from the rhizosphere soil of maize plants by Wet Sieving and Decanting technique (Gerdemann et al., 1963). This technique was used to remove the clay and sand particles while retaining spores and other similar sized soil and organic matter particles on sieves of various diameters (Singh et al., 2016). 


\section{Morphological characterisation of VAM}

The VAM fungal spores collected on filter paper by Wet Sieving and Decanting technique were observed under microscope. These spores were stained with trypan blue stain. Mycorrhizal fungal structure in roots is usually not observed without appropriate staining because internal structures are obscured by the natural pigments and cell contents within roots. The spores and roots of trap plants were stained by trypan blue staining method described by Phillips and Hayman (Phillips et al., 1970).

\section{In vitro cultivation of VAM}

\section{Cultivation in liquid media}

Isolated VAM fungal spores were pregerminated. These spores were cultivated in Cooke Rose Bengal liquid medium with incubation at $24 \pm 2^{\circ} \mathrm{C}$ in dark conditions for 24-48 hours. Liquid medium were harvested at regular intervals for investigating various fungal structures (Cooke, 1954; Singh et al., 2016).

\section{Cultivation on solid (artificial) media}

Pre-germinated spores were inoculated on Cooke Rose Bengal agar having formula Per litre, Soy Peptone $-5.0 \mathrm{~g}$, Dextrose $-10.0 \mathrm{~g}$, Monopotassium Phosphate, $1.0 \mathrm{~g}$, Magnesium Sulfate $0.5 \mathrm{~g}$, Agar, $20.0 \mathrm{~g}$ and Rose Bengal $35.0 \mathrm{mg}$, allowing incubation at $24 \pm 2^{\circ} \mathrm{C}$ in dark conditions for 24-48 hours. Fungal biomass produced was studied at regular intervals (Cooke, 1954; Singh et al., 2016).

\section{Cultivation on solid (natural) media}

Hydroponic system work on the principle that plants grow in a sterile, soil-less medium that allows delivery of nutrients to the roots directly from a nutrient-enriched water solution. Hydroponic system provides nutrients to the plants in the form of thin layer on the roots which results in greater proliferation of roots, production of higher number of spores/cm of infected roots. It facilitates better aeration than soil (Sharma et al., 2000). Pregerminated seeds of Maize, Rice and Wheat seeds were used for hydroponics.

\section{In vivo biological efficacy}

In vitro cultivated isolates of VAM were used to inoculate seeds of trap plants. Trap culture pots were allowed to grow for about a month (Tanzima Yeasmin et al., 2004) and later left to dry under shade. Infectivity of plant roots with VAM was checked (Yagoob Habizadeh, 2015).

Length and dry weight of plants were determined after harvesting. These measurements were further used for calculating shoot: root ratio and other infectivity assays. Roots were washed, stained and processed for estimation of primary infection points (Tanzima Yeasmin et al., 2004; Yagoob Habizadeh 2015)

\section{Mycorrhizal Dependency (M.D)}

Relative field mycorrhizal dependency (RFMD) index was determined by expressing the difference between dry weights of mycorrhizal plants with that of nonmycorrhizal ones and expressed as percentage of dry weight of mycorrhizal plants.

Mycorrhizal dependency values were calculated using method devised by Plenchette (Planchtte et al., 1983).

(Dry weight of mycorrhizal plant) (Dry weight of non-mycorrhizal plant)

\% RFMD= ------- x 100

Dry weight of mycorrhizal plant 
Measurement of mycorrhizal root colonization was done after cleaning and staining the roots, spreaded randomly was selected, root segments (1 cm in length) were stained with trypan blue, mounted 1-2 root pieces on each glass slide, observed them and estimated the proportions of each root segment consisting of vesicles, arbuscules and hyphae (Phillips et al., 1970; Tabassum Yaseen et al., 2011).

\section{Results and Discussion}

\section{Isolation of VAM}

The spores which were isolated from the soil by wet sieving and decanting technique were stained with trypan blue and observed under microscope.

Blue coloured, spherical spores which were present singly and in clusters (Pawlowska et al., 2011) were observed as shown in figure 1 .

\section{Morphological characterization of VAM}

\section{On liquid and Solid (artificial) media}

Thin hyphal networks of VAM were observed in liquid media whereas thick hyphae were observed on synthetic media under microscope on staining with trypan blue as shown in figure 2.

The hyphae showed dichotomous branching. Terminal swellings were observed at the end of many hyphae (Brundrett, 1991).

\section{On solid (natural) media}

Infection of roots with VAM was observed. The VAM invaded the roots with multiple penetration points and infected up to the cortex region of the roots as shown in figure 3 .

The VAM infection was considerably high in maize roots as compared to wheat and rice.

\section{In vitro cultivation of VAM on synthetic media}

Isolated VAM spores were cultivated in liquid and solid Cooke Rose Bengal medium. After 2 -3 days incubation at room temperature in dark, turbidity was observed in inoculated tubes and off-white matty lawn growth was observed on solid medium plates (Figure 4-A and 4-B).

Cultivated growth was stained with Trypan Blue stain. The hyphae of VAM growing on solid media were thick. The vesicles formation were observed after $15^{\text {th }}$ days on solid agar media as shown in figure 4-C.

\section{In vivo biological efficacy}

In vitro cultivated isolates of VAM were inoculated onto seeds of trap plants. The plant growth parameters were measured after 30 days. Plant shoot length, root length and dry weight were determined. After drying the samples in oven for $72 \mathrm{~h}$ at $70^{\circ} \mathrm{C}$, the dry weight was measured for maize, rice and wheat plants (Figure 5).

From table 1 and figure 6 , the overall plant height of maize plants was observed to be more than rice and wheat plants. The test (mycorrhizal) plants of maize, rice and wheat had increased plant heights by 43.5, 65.1 and $41.4 \%$ respectively as compared to the plant heights of control (non-mycorrhizal) plants (Tabassum Yaseen et al., 2011). The percent increase in plant height was maximum for rice. From tables 2 and 3, the root and shoot lengths as well as dry weights of Test (Mycorrhizal) plants were observed to be more than Control (Non-Mycorrhizal) plants (Yagoob Habizadeh, 2015). Due to VAM inoculum, the total biomass is a gain factor of plant height, leaves and roots, which results to more root-shoot length and dry weight in test plants than that of control plants. 
Table.1 Comparison of plant height between test and control plants

\begin{tabular}{|c|c|c|c|c|c|}
\hline Sr. No. & $\begin{array}{l}\text { Plant } \\
\text { variety }\end{array}$ & Treatment & $\begin{array}{l}\text { Plant } \\
\text { height (cm) }\end{array}$ & $\begin{array}{l}\text { Average plant } \\
\text { height }(\mathrm{cm})\end{array}$ & $\begin{array}{l}\% \\
\text { increase }\end{array}$ \\
\hline 1 & Maize & Control & $\begin{array}{l}42.4 \\
40.6 \\
38.8\end{array}$ & $40.6 \pm 1.8$ & - \\
\hline 2 & Maize & Test & $\begin{array}{l}57.0 \\
55.4 \\
64.1\end{array}$ & $58.3 \pm 4.6$ & 43.5 \\
\hline 3 & Rice & Control & $\begin{array}{l}15.1 \\
16.6 \\
14.8\end{array}$ & $15.5 \pm 0.9$ & - \\
\hline 4 & Rice & Test & $\begin{array}{l}25.2 \\
22.3 \\
29.3\end{array}$ & $25.6 \pm 3.5$ & 65.1 \\
\hline 5 & Wheat & Control & $\begin{array}{l}23.6 \\
26.1 \\
30.8\end{array}$ & $26.8 \pm 3.6$ & - \\
\hline 6 & Wheat & Test & $\begin{array}{l}38.0 \\
41.1 \\
34.8\end{array}$ & $37.9 \pm 3.1$ & 41.4 \\
\hline
\end{tabular}

Table.2 Comparison of shoot length and dry weight of various plants

\begin{tabular}{|c|c|c|c|c|c|}
\hline Sr. No. & $\begin{array}{l}\text { Plant } \\
\text { variety }\end{array}$ & Treatment & $\begin{array}{l}\text { Shoot } \\
\text { length (cm) }\end{array}$ & $\begin{array}{l}\text { Average shoot } \\
\text { length }(\mathrm{cm})\end{array}$ & $\begin{array}{l}\text { Average shoot } \\
\text { dry weight (g) }\end{array}$ \\
\hline 1 & Maize & Control & $\begin{array}{l}29.1 \\
30.6 \\
32.1\end{array}$ & $30.6 \pm 1.5$ & $0.72 \pm 0.03$ \\
\hline 2 & Maize & Test & $\begin{array}{l}42.0 \\
40.0 \\
46.6\end{array}$ & $42.8 \pm 3.3$ & $1.96 \pm 0.005$ \\
\hline 3 & Rice & Control & $\begin{array}{l}13.0 \\
14.5 \\
12.0\end{array}$ & $13.1 \pm 1.2$ & $0.21 \pm 0.01$ \\
\hline 4 & Rice & Test & $\begin{array}{l}17.0 \\
17.8 \\
25.5\end{array}$ & $20.1 \pm 4.6$ & $0.34 \pm 0.04$ \\
\hline 5 & Wheat & Control & $\begin{array}{l}20.0 \\
22.0 \\
27.0\end{array}$ & $23.0 \pm 3.6$ & $0.17 \pm 0.03$ \\
\hline 6 & Wheat & Test & $\begin{array}{l}28.6 \\
29.7 \\
25.3\end{array}$ & $27.8 \pm 2.2$ & $0.35 \pm 0.01$ \\
\hline
\end{tabular}


Table.3 Comparison of root length and dry weight of various plants

\begin{tabular}{|c|c|c|c|c|c|}
\hline Sr. No. & $\begin{array}{l}\text { Plant } \\
\text { variety }\end{array}$ & Treatment & $\begin{array}{l}\text { Root length } \\
(\mathrm{cm})\end{array}$ & $\begin{array}{l}\text { Average root } \\
\text { length }(\mathrm{cm})\end{array}$ & $\begin{array}{l}\text { A verage root } \\
\text { dry weight (g) }\end{array}$ \\
\hline 1 & Maize & Control & $\begin{array}{l}8.7 \\
11.0 \\
10.2\end{array}$ & $9.6 \pm 1.1$ & $0.66 \pm 0.06$ \\
\hline 2 & Maize & Test & $\begin{array}{l}15.0 \\
15.4 \\
17.5\end{array}$ & $15.9 \pm 1.3$ & $1.03 \pm 0.03$ \\
\hline 3 & Rice & Control & $\begin{array}{l}2.1 \\
2.1 \\
2.8\end{array}$ & $2.3 \pm 0.4$ & $0.14 \pm 0.02$ \\
\hline 4 & Rice & Test & $\begin{array}{l}8.2 \\
4.5 \\
3.8\end{array}$ & $5.5 \pm 2.3$ & $0.20 \pm 0.02$ \\
\hline 5 & Wheat & Control & $\begin{array}{l}3.6 \\
4.1 \\
3.8\end{array}$ & $3.8 \pm 0.25$ & $0.16 \pm 0.02$ \\
\hline 6 & Wheat & Test & $\begin{array}{l}9.4 \\
11.4 \\
9.5\end{array}$ & $10.1 \pm 1.1$ & $0.31 \pm 0.03$ \\
\hline
\end{tabular}

Table.4 Comparison of shoot-root ratio, \% root colonization and \% RFMD

\begin{tabular}{|l|l|l|l|l|l|}
\hline Sr. No. & VARIETY & TREATMIENT & $\begin{array}{l}\text { SHOOT: } \\
\text { ROOT } \\
\text { RATIO }\end{array}$ & $\begin{array}{l}\text { \% ROOT } \\
\text { COLONIZATION }\end{array}$ & \% RFMID \\
\hline $\mathbf{1}$ & Maize & Control & $1.0 \pm 0.15$ & 0.0 & 0.0 \\
\hline $\mathbf{2}$ & Maize & Test & $1.9 \pm 0.2$ & $80 \pm 4.58$ & $53.8 \pm 1.04$ \\
\hline $\mathbf{3}$ & Rice & Control & $1.5 \pm 0.25$ & 0.0 & 0.0 \\
\hline $\mathbf{4}$ & Rice & Test & $1.7 \pm 0.58$ & $70 \pm 10.59$ & $35.1 \pm 1.01$ \\
\hline $\mathbf{5}$ & Wheat & Control & $1.0 \pm 0.15$ & 0.0 & 0.0 \\
\hline $\mathbf{6}$ & Wheat & Test & $1.1 \pm 0.25$ & $70 \pm 9.00$ & $50.0 \pm 2.00$ \\
\hline
\end{tabular}

Fig.1 Microscopic image of isolated VAM spores

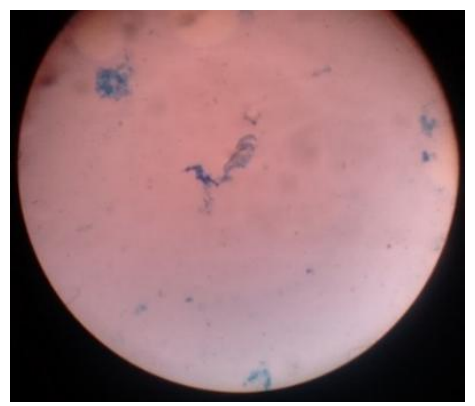


Fig.2 Microscopic images of cultivated VAM in liquid and solid media

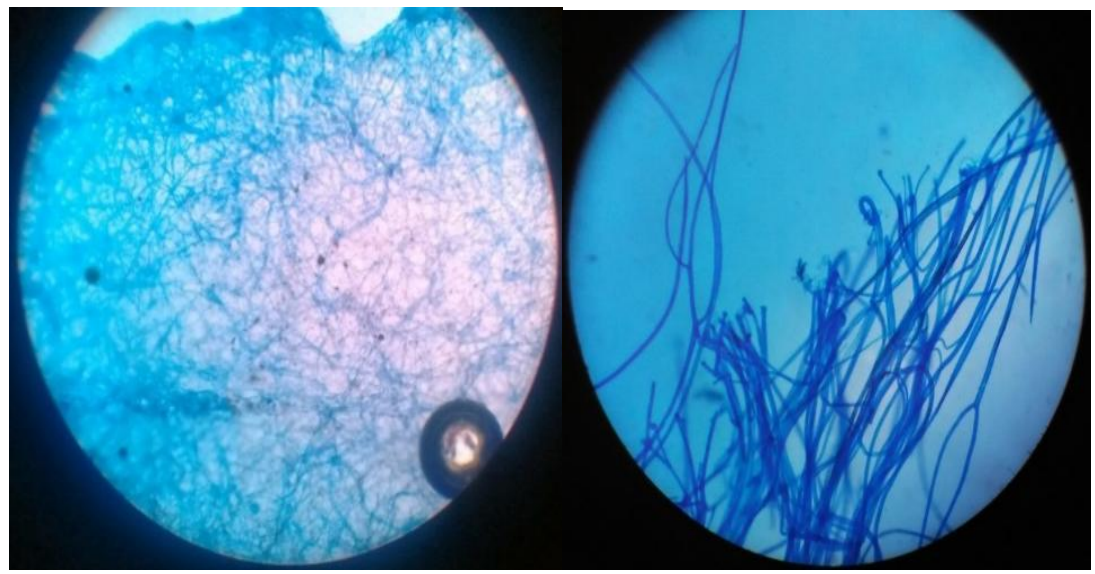

Fig.3 Microscopic image of infected maize plant root

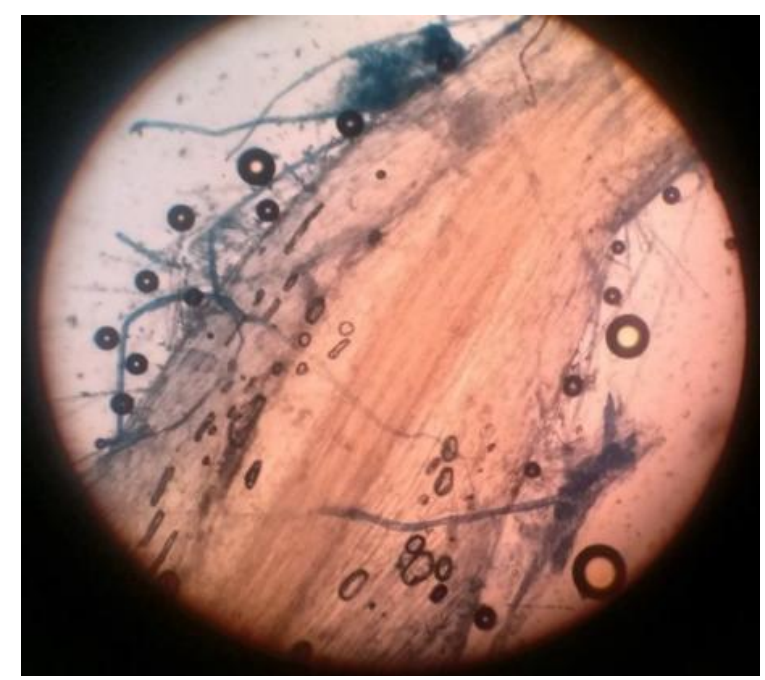

Fig.4 Growth of VAM spores in synthetic medium (A-Liquid, B- Solid, C-Vesicles).

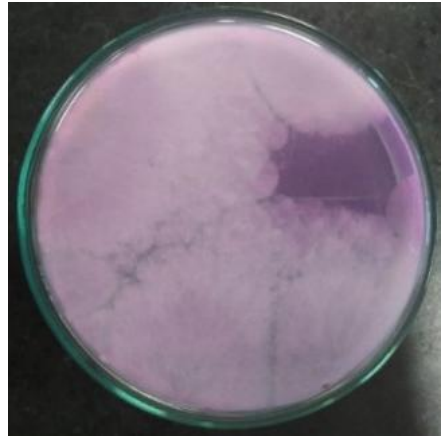

A-Control

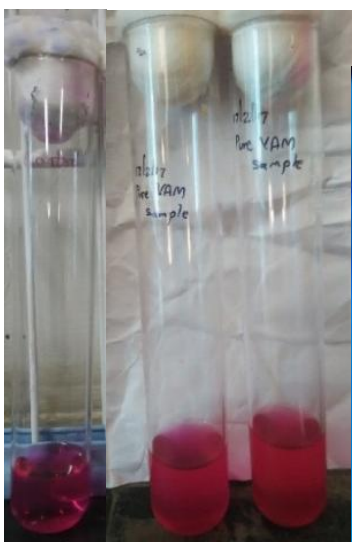

A-Test
B

C 
Fig.5 Comparative observations of maize, wheat and rice plants

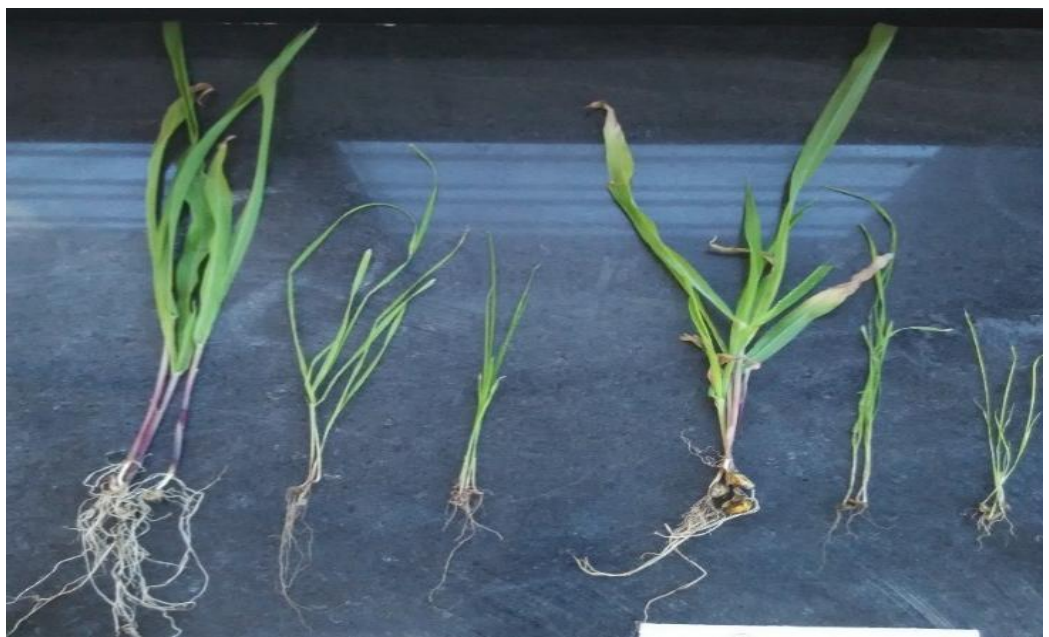

Test trap plants Control trap plants (maize, wheat, rice) (maize, wheat, rice)

Fig.6 Comparative in-vivo biological efficacy of VAM treated plants
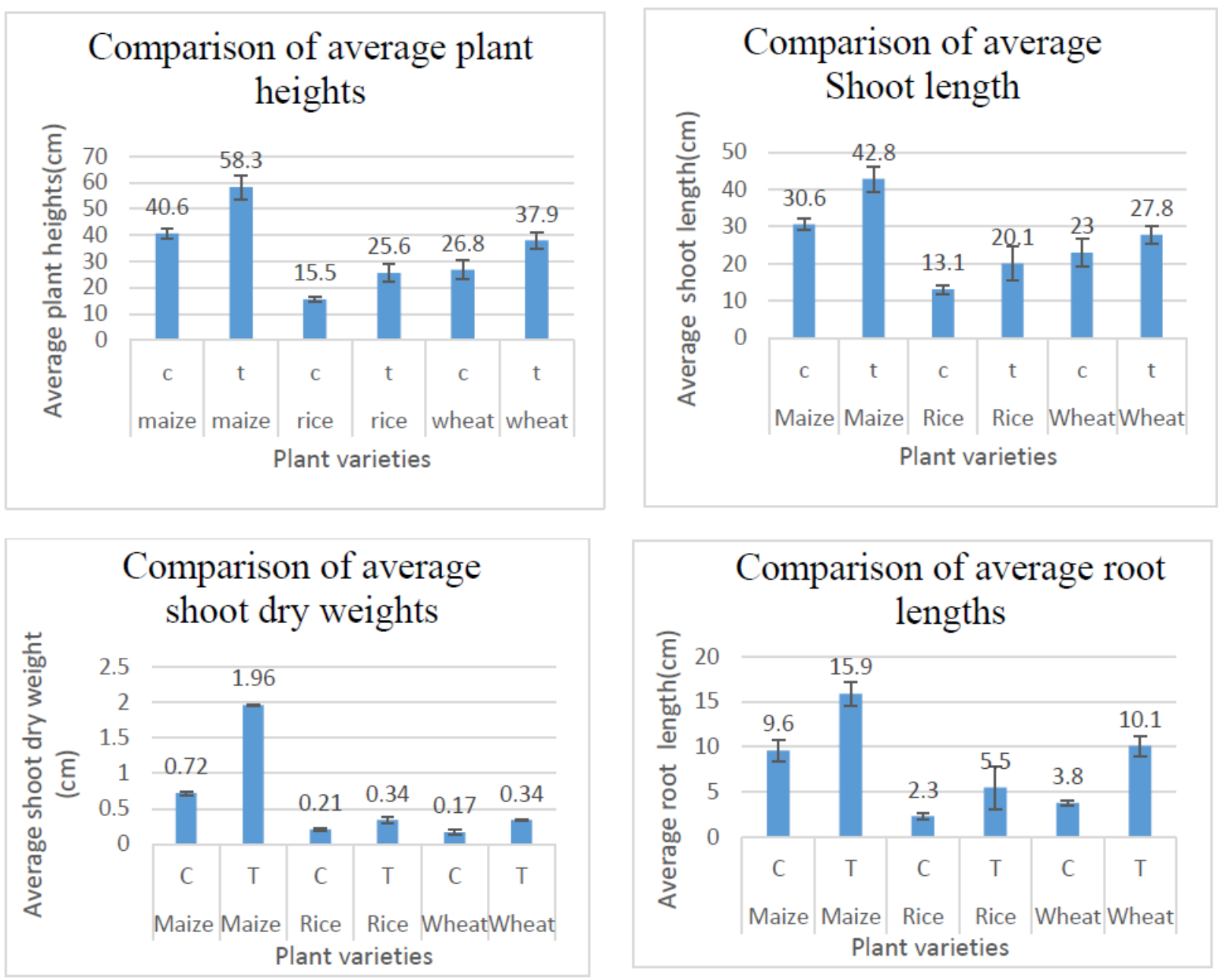

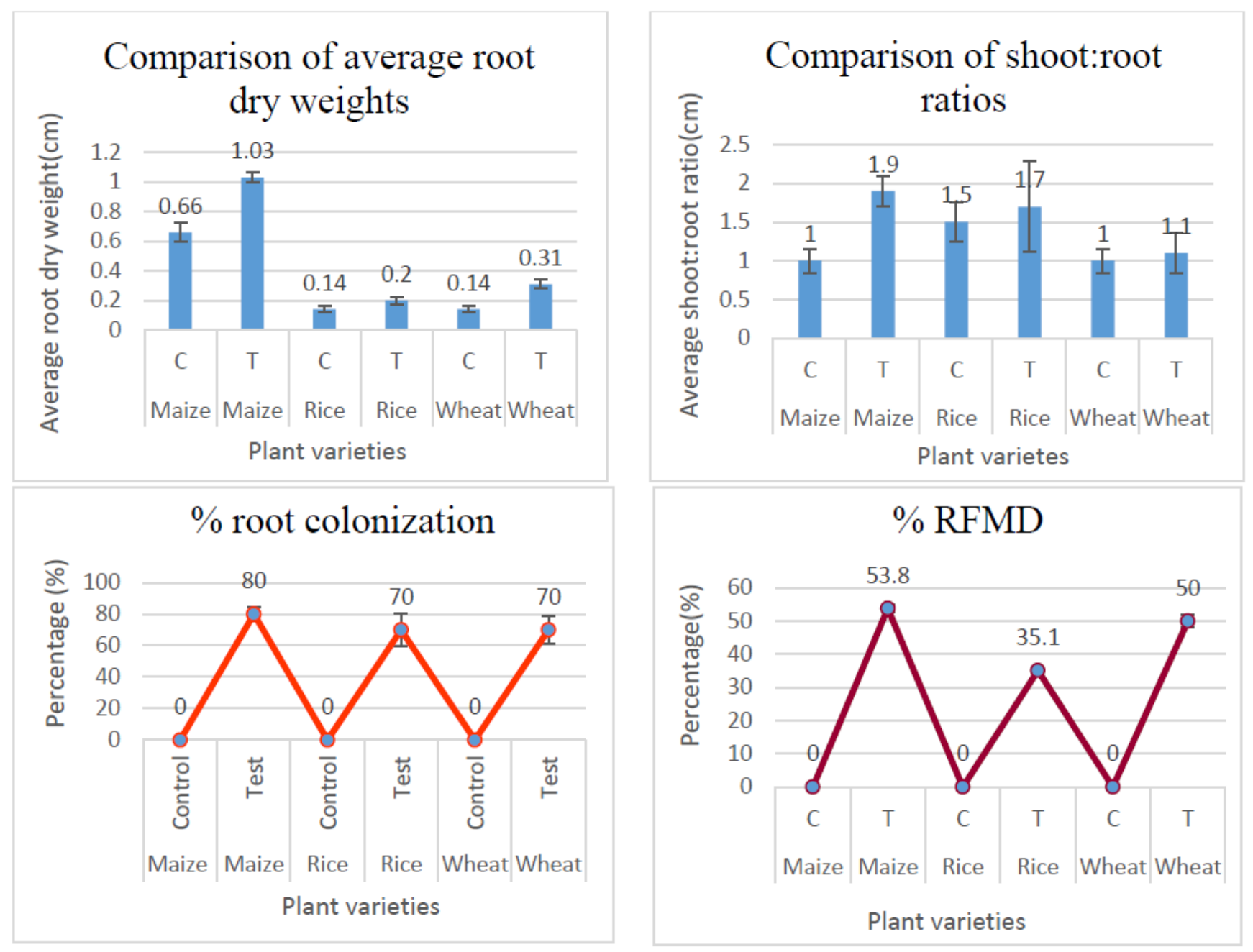

Fig.7 Wheat, rice and maize root infected with VAM

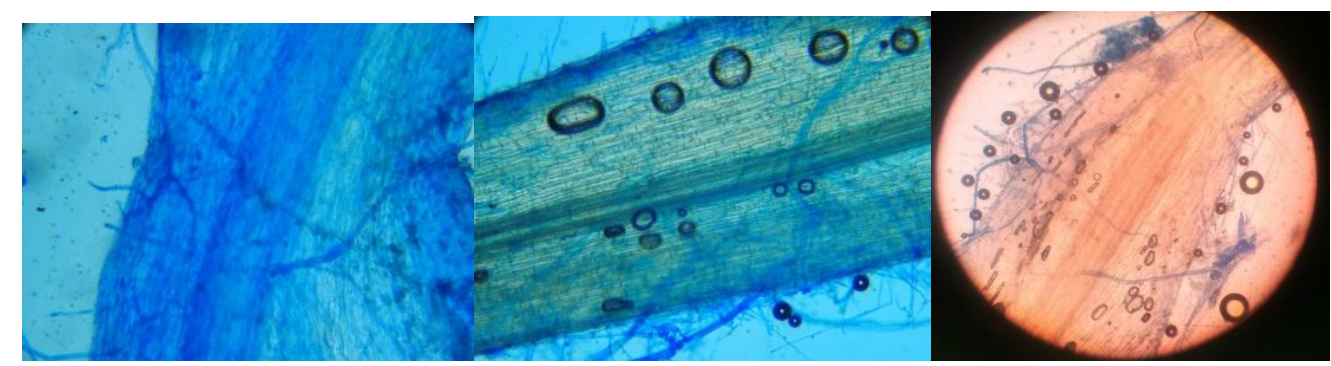

From table 4, it was observed that test (Mycorrhizal) plants showed greater Shoot: Root ratio than control (Non-Mycorrhizal) plants. Moreover, the $\%$ root colonization and $\%$ RFMD were observed to be maximum in test plant of Maize plants, followed by Wheat plants and minimum in Rice plants. No root colonization and Mycorrhizal dependency was observed in control (Non-Mycorrhizal) plants (Tanzima Yeasmin et al., 2004; Yagoob Habizadeh, 2015; Tabassum Yaseen et al., 2011). All wheat, maize and rice seedlings inoculated with germinated spores of VAM developed mycorrhizae, while no mycorrhizae were observed in uninoculated control pots. The test plants showed more 
plant height and dry weight as compared to control plants. Percent root colonization (Mosse et al., 1975), shoot: root ratio and \% RFMD were observed to be maximum in test plants of maize, followed by wheat and minimum in rice. The overall percent increase in all the observed parameters was more in rice, compared to maize and minimum in wheat test plants (Tanzima Yeasmin et al., 2004; Yagoob Habizadeh, 2015; Tabassum Yaseen et al., 2011)

Infection of various plant roots stained with trypan blue are shown in figure 7.

It may be concluded from the present study, that the chemical composition of synthetic growth medium used for VAM production influenced its growth. The cultivated VAM spores were capable of infecting maize, rice and wheat trap plant roots. Mycorrhizal trap cultures had more positive effect on maize plants than rice and wheat. Maize plants showed higher percentage of overall growth parameters than rice and wheat in response to mycorrhizal inoculation. Overall fungus inoculation significantly increased plant biomass. For mycorrhizal plants, mycorrhizal dependency and root colonization values were calculated. These results confirm that VAM cultivated on synthetic media can be used as an excellent medium for mass production of highly potent pure culture and restrict use of chemical fertilizers.

\section{References}

Amutha R., Karunakaran S., Dhanasekaran S., Hemalatha K., Monica R., Shanmugapriya $\mathrm{P}$. and Sornalatha $\mathrm{T}$. (2014): Isolation and mass production of biofertilizer (Azotobacter and Phosphobacter). International Journal of latest research in Science and Technology. 3(1), 79-81.
Aroca R., Varnieri P. and Ruiz-Lozano J.M. (2008): Mycorrhizal and nonmycorrhizal Lactuca sativa plants exhibit contrasting responses to exogenous ABA during drought stress and recovery. Journal of Experimental Botany, 59(8): 2029-2041.

Bhowmik S.N. and Singh C.S. (2004): Mass multiplication of AM inoculum: Effect of plant growth-promoting rhizobacteria and yeast in rapid culturing of Glomus mosseae. Current Science, 86(5), 705709.

Brundrett M.C. (1991): Mycorrhizas in natural ecosystems. Advances in Ecological Research. Academic Press, London. Vol. 21, 171-313.

Cooke, W.B. (1954): The use of antibiotics in media for the isolation of fungi from polluted water. Antibiotic Chemotherapy (Basel), 4, 657-662.

Gerdemann, J.W. and Nicolson, T.H (1963): Spores of mycorrhizal Endogone extracted from soil by wet sieving and decanting. Trans. Br. Mycol. Soc., 46, 235-244.

Jha, K.S. and Kumar N. (2011): Potential of Mycorrhizal fungi in ecosystem: A review. International Journal of Research in Botany; 1(1): 1-7.

Mosse B. and Herper C. (1975): VesicularArbuscular Mycorrhizal infection in organ culture. Physiol. Plant Pathol. 5, 215-223.

Pawlowska T.E., Douds D.D. and Charvat I. (1999): In vitro propagation and life cycle of the Arbuscular mycorrhizal fungus Glomus etunicatum. Mycol. Res. 103(12), 1549-1556.

Phillips, J.M. and Hayman, D.S. (1970): Improved procedure for clear staining parasitic and vesiculararbuscularmycorrhizal fungi for rapid assessment of infection. Trans. $\mathrm{Br}$. Mycol. Soc., 55, 158-161. 
Planchette C.A., Foretin A. and Furlan V. (1983): Growth response of several plant species to mycorrhizae in a soil of moderate P-fertility. I. Mycorrhiza under field conditions. Plant and Soil. 70: 199-209.

Pringle A., Bever J.D., Gardes M., Parrent J.L., Rillig M.C. and Klironomos J.N. (2009): Mycorrhizal symbiosis and Plant Invasions. The Annual Review of Ecology, Evolution and Systematics, 40:699-715.

Sharma A.K., Singh C. and Akhauri P. (2000): Mass culture of Arbuscular Mycorrhizal Fungi and their role in Biotechnology. Proc. Indian natnSci Acad. (PINSA) B66 Nos4 \& 5, 223-238.

Singh G., Sharma P. and Sharma S. (2016): Role of growth media on phytopromotional potential of symbiotic fungus Piriformospora indica. Journal of Environmental Biology, 37, 889-894.

Smith S.E. and Smith F.A. (2011): Roles of arbuscular mycorrhizas in plant nutrition and growth: new paradigms from cellular to ecosystem scales. Ann. Rev. Plant Bio. I. 62, 675-682.

Tabassum Yaseen, Tanvir B. and Farrukh Hussian (2011): Effect of Arbuscular mycorrhizal inoculation on nutrient uptake, growth and productivity of cowpea (Vigna unguiculata) verities. African Journal of Biotechnology, 10 (43), 8593-8598.

Tanzima Yeasmin, Parmita Zaman, Ataur Rahman, NurulAbsar and Nurus Saba Khanum (2004): Arbuscular mycorrhizal fungus inoculum production in rice plants. African Journal of Agricultural Research, 2(9), 463-467.

Yagoob Habizadeh (2015): The effects of Arbuscular mycorrhizal fungi and phosphorus level on dry matter production and root traits in cucumber (Cucumis sativus L.). African Journal of Environmental science and technology, $9(2), 65-70$.

\section{How to cite this article:}

Bholay, A.D., Sophia Barbosa and Kirti Jadhav. 2018. In vitro Cultivation of VesicularArbuscular Mycorrhizal Fungi and its Biological Efficacy. Int.J.Curr.Microbiol.App.Sci. 7(03): 931-941. doi: https://doi.org/10.20546/ijcmas.2018.703.110 